\title{
A Contrastive Study of Gift-Giving Between Chinese and Germans
}

\author{
PENG Mei \\ Shanghai International Studies University, Shanghai, China
}

\begin{abstract}
This study compares the practice of gift-giving between Chinese and Germans from the perspective of intercultural communication. Starting from two real cases which resemble each other but set in sharply different cultural backgrounds, the author conducted a small-scale comparative study based on her reflections in hope of exploring the deep underlying cultures and values behind gift-giving in current China and Germany. With a questionnaire survey and interviews as the main instruments to collect both qualitative and quantitative data, the author made some interesting and useful findings after carefully analyzing, discussing, and summarizing the questionnaire and interview results. Based on the conclusions, the researcher discussed some possible teaching implications in intercultural foreign language teaching.
\end{abstract}

Keywords: intercultural communication, gift-giving, Guanxi, face, FL teaching

\section{Introduction}

Today's world is characterized as a "global village" because of the rapid expansion of worldwide transportation and communication networks. Accordingly, cultural exchanges and communication across nations have become increasingly frequent, necessary, and important, which heightens our awareness of the need for understanding other cultures and their people (Gudykunst \& Kim, 2007). Obviously, in a world of independence, the ability to understand and communicate effectively with people from different cultures takes on great urgency. Culture and communication are so closely intertwined that Hall (1959) holds that "culture is communication" and "communication is culture". It was just against this background that the study of intercultural communication (abbreviated as "IC") started to come into sight. Although it has been a relatively new and young field of enquiry, which originated from the United States, it has evolved into an independent, vigorous and promising discipline over the past fifty years or so (ZHANG, 2007). Gudykunst and Kim (2007) define intercultural communication as "a transactional, symbolic process involving the attribution of meaning between people from different cultures. In other words, we can simply put it as "communication between people from different cultures" (Gudykunst \& Kim, 2007, p. 18). As is known to all, the Chinese government has always attached great importance to foreign language teaching and the Ministry of Education has been making unremitting efforts to make reformations in foreign language teaching at all levels. In the newly released College English Teaching Guidelines, it is made very clear that raising learners' IC awareness and enhancing their IC competence should be one of the main objectives in the successful teaching of foreign language in China (JIA, 2015).

PENG Mei, associate professor, Ph.D., Continuing Education College, Shanghai International Studies University. 


\section{Research Background}

\section{Two Cases in Intercultural Communication}

$\mathrm{Li}$, a friend of the author, is an international student in Germany. There, he made a good German friend-Stefan, who was not only friendly and helpful but also interested in Chinese culture and the language. As a stranger in a totally different country, Li had a hard time in the beginning. Thanks to Stefan, who offered his help in many ways, Li soon became used to his life and things began to work out more smoothly. One year later, Stefan was going to Shanghai to learn Chinese. Feeling greatly indebted and thankful to Stefan, Li thought he should, according to the Chinese customs, do something for Stefan to show his gratitude and friendship. So, he invited Stefan to go shopping with him saying he wanted to buy a present for a friend and hoped to get some good advice from Stefan. Being pleased to help his Chinese friend, Stefan agreed without hesitation. In a shop, Li found a very fancy and expensive multi-functional pen. He asked Stefan how he felt like that pen. Stefan told him that maybe the price was a little too high, but if Li liked that and the friend was very special, it was ok. Therefore, Li bought this pen and they left the shop. Feeling surprised and curious, Stefan asked Li whom on earth he was sending this costly gift to. At this, Li suddenly beamed at Stefan and said, "It's for you, Stefan. Thank you very much for all the things you've done for me!". With these words, he put the package into Stefan's hands. However, what Li saw on Stefan's face was not smile or appreciation but an expression of great shock and anger! Then came Stefan's choking words, "No, no, I can't take this. I really can't!". Thinking Stefan was being polite, Li made up his mind to be more compelling so that his friend would accept this gift. But the more Li insisted, the more firmly Stefan refused. Both became very embarrassed and felt a bit awkward. Fortunately, Stefan understood that Li meant well, so he decided to have a serious talk with him. After the talk, Li seemed to understand the problem and Stefan eventually accepted the gift.

Interestingly, a German friend of the author, Anja, who works in the German Center in Shanghai, told the researcher a similar true story between her German colleague Katrine and a Chinese boy called Wang. The differences are that this event occurred in China and it was the German girl who did the same thing as my friend Li to her Chinese friend. However, the result was strikingly different! Instead of feeling shocked and uncomfortable, the Chinese boy joyfully accepted the gift!

\section{Reflections on the Two Cases}

These two incidents triggered the author's curiosity and interest in the different cultures of gift-giving between the Chinese and the Germans. Reflecting on these two real cases occurring in different cultural backgrounds, the author found herself constantly thinking about several questions: Why would Stefan and Wang respond sharply differently in a similar situation? Why would Li choose such a way to give the gift to Stefan? Is it related to any deep values in the Chinese culture? What does the price of gifts indicate in Chinese and Western gift-giving culture? How do the Chinese and Germans view gift-giving in their respective way? Are there any deep values connected with it? With these questions in mind, the author decided to conduct a tentative, small-scale empirical research into this area to work out her confusion. By comparing the gift-giving practice and exploring the underlying values between the Chinese and the Germans from the perspective of IC, we hope to gain more insights in this field and help us communicate more successfully and act more appropriately on similar social occasions, and meanwhile, the findings may provide desirable teaching materials and implications in intercultural foreign language teaching, which is considered as an integral part of foreign language teaching in China (ZHANG, 2007). 


\section{Research Design}

\section{Research Questions}

Based on the precious research of some Chinese and Western scholars on IC (Boye Lafayette De Mente, 1989; Hu \& Comelius, 1991; Seligman, 1999), the researcher posed three research questions: (1) What are the Chinese and Westerners' viewpoints on sending gifts? (2) How is meaning expressed differently through gifts in China and Germany? (3) What is the underlying value behind gift-giving in both China and the Westerns countries?

\section{Participants}

The participants include 30 Chinese and 30 Germans. The 30 Chinese ( 25 females and 5 males) are from different provinces of China and they age from 18 to 35. They are either college students or professionals in all walks of life. The 30 Germans (13 females and 17 males) are either overseas students in universities in Shanghai or employees in the German Center. They age from 20 to 40. So technically speaking, the participants belong to the same age group, with similar educational background.

\section{Research Methods and Instruments}

By comparing and contrasting two different groups of data, which include both quantitative and qualitative ones, this study is descriptive and explorative in nature.

The instruments consist of (1) a questionnaire (two versions) and (2) semi-structured interviews.

\section{Data Collection Procedures}

The researcher first designed a questionnaire with two versions of exactly the same contents, one in Chinese, the other in English. She then tried them among some of her colleagues and collected some good feedback. Next she presented them to an American professor who works in the author's university as a famous expert on IC Studies to seek for further suggestions. With his help and supervision, the final versions were completed and were thought to be suitable and effective. It consisted of 11 questions related to gift-giving (see Appendix). She then distributed the questionnaires to 31 Chinese and 31 Germans by convenience sampling and eventually collected 30 valid copies from each group.

After the survey, the researcher interviewed eight participants, four from each group to collect more qualitative data. In this way, the researcher was able to explore more deeply the reasons for the participants' choices in the questionnaire.

\section{Data Analysis and Discussion}

\section{Analysis of the Questionnaire}

As can be seen in Table 1, in many cases, the Chinese have different choices from the Germans. Both the Chinese and German participants hold that sending presents to each other is an important means of social contact, which can improve interpersonal relationship. But when asked to what degree they agree with the first statement, $50 \%$ of Chinese participants believe that presents are important measures to prove whether one is taken seriously in another's heart, while only $26.67 \%$ of the Germans ones think so. This might indicate that the Chinese tend to use tangible things to measure abstract feelings or thoughts, whereas the Germans may prefer to use other things rather than material stuff to handle interpersonal relationship. 
Table 1

Results of the Questionnaires

\begin{tabular}{|c|c|c|c|c|c|c|c|c|c|c|}
\hline \multirow[b]{2}{*}{ Items } & \multirow[t]{2}{*}{ Choice } & \multicolumn{4}{|c|}{ Chinese $(n=30)$} & \multicolumn{5}{|c|}{ Germans $(n=30)$} \\
\hline & & 4 & 3 & 2 & 1 & 5 & 4 & 3 & 2 & 1 \\
\hline Qu. 1 & $10.00 \%$ & $40.00 \%$ & $13.33 \%$ & $30.00 \%$ & $6.67 \%$ & $6.67 \%$ & $20.00 \%$ & $20.00 \%$ & $36.67 \%$ & $16.67 \%$ \\
\hline Qu. 2 & $20.00 \%$ & $23.33 \%$ & $10.00 \%$ & $33.33 \%$ & $10.00 \%$ & $6.67 \%$ & $30.00 \%$ & $20.00 \%$ & $30.00 \%$ & $16.67 \%$ \\
\hline Qu. 3 & $20.00 \%$ & $43.33 \%$ & $16.67 \%$ & $20.00 \%$ & $0.00 \%$ & $6.67 \%$ & $13.33 \%$ & $40.00 \%$ & $30.00 \%$ & $10.00 \%$ \\
\hline Qu. 4 & $50.00 \%$ & $33.33 \%$ & $13.33 \%$ & $3.33 \%$ & $0.00 \%$ & $40.00 \%$ & $26.67 \%$ & $10.00 \%$ & $16.67 \%$ & $6.67 \%$ \\
\hline Qu. 5 & $60.00 \%$ & $16.67 \%$ & $10.00 \%$ & $13.33 \%$ & $0.00 \%$ & $33.33 \%$ & $33.33 \%$ & $6.67 \%$ & $20.00 \%$ & $6.67 \%$ \\
\hline Qu. 6 & $50.00 \%$ & $36.67 \%$ & $6.67 \%$ & $6.67 \%$ & $0.00 \%$ & $6.67 \%$ & $23.33 \%$ & $26.67 \%$ & $36.67 \%$ & $6.67 \%$ \\
\hline Qu. 7 & $16.67 \%$ & $50.00 \%$ & $6.67 \%$ & $26.67 \%$ & & $0.00 \%$ & $60.00 \%$ & $3.33 \%$ & $36.67 \%$ & \\
\hline Qu. 8 & $66.67 \%$ & $6.67 \%$ & $26.67 \%$ & $0.00 \%$ & & $50.00 \%$ & $20.00 \%$ & $3.33 \%$ & $26.67 \%$ & \\
\hline Qu. 9 & $76.67 \%$ & $3.33 \%$ & $10.00 \%$ & $10.00 \%$ & & $53.33 \%$ & $30.00 \%$ & $16.67 \%$ & $0.00 \%$ & \\
\hline Qu. 10 & $63.33 \%$ & $20.00 \%$ & $10.00 \%$ & $6.67 \%$ & & $90.00 \%$ & $0.00 \%$ & $3.33 \%$ & $6.67 \%$ & \\
\hline Qu. 11 & $10.00 \%$ & $70.00 \%$ & $20.00 \%$ & $0.00 \%$ & & $13.33 \%$ & $73.33 \%$ & $13.33 \%$ & $0.00 \%$ & \\
\hline
\end{tabular}

According to the feedback from question 2, we can see that in current China, nearly half of the young generation $(43.33 \%$ ) use the amount of money to weigh the degree of closeness of a relationship and they think money seems to be an important channel to convey meaning. However, a same number of the Chinese participants hold the opposite opinion. Contrastively, 36.67\% of German subjects agree with the statement while $46.67 \%$ of them disagree. This might also show that the Germans have other ways to measure the degree of closeness of interpersonal relationships.

Comparing the results from question 3 and 4 , we find that interestingly, although $83.33 \%$ of the Chinese participants and $66.67 \%$ of the German participants agree that they consider the suitability of gifts more importantly regardless of the price; more than half of the Chinese participants (63.33\%) admit expensive gifts are often used to demonstrate the significance attached to one's relationship with the recipient (Qu. 3). It is the researcher's assumption that for most of the Chinese people, the more expensive a gift is, the more meaning it entails. In this way, the givers and the recipient would both feel having gained face and their relationship is likely to develop deeper and better. On the contrary, only $20 \%$ Germans would feel the same. They seem to highlight more on the suitability of the gift or other nonmaterial things to develop their relationship with others.

Surprisingly, more Chinese participants $(76.67 \%)$ than German ones $(66.66 \%)$ show that if possible, they would prefer to send self-made gifts than purchased ones in that self-made gifts are more personal and precious. This may suggest that in China, the young generation is becoming more individualistic and less traditional. But as a matter of fact, the results just display what the Chinese hope to do, but not what they really have been doing in reality. While later from the interviews, the research was told that in Germany, a lot of people do often send self-made gifts. It is a common practice.

The results of question 6 verify another possible motive for the giving of gifts in China-as tokens of gratitude or thankfulness, whereas only $30 \%$ Germans do the same. We might understand it in this way: The Chinese people are usually conditioned to express appreciation in tangible ways. When they do someone a favor, they expect appreciation to be expressed in some very concrete ways. As Confucius said, "lai er bu wang fei li ye" (One should return as good as one receives; it is impolite not to reciprocate). With this influence, many Chinese have subconsciously become accustomed to expressing or appreciating gratitude by giving or accepting gifts. This fixed norm has been taken for granted by the Chinese but is neglected in cross-cultural 
communication. The Germans, however, are deeply affected by The Bible. Just as Jesus said, "But love your enemies, do good to them, and lend to them without expecting to get anything back" (The Bible, Luke 6: 35) ${ }^{1}$ Perhaps we can say that they are brought up to learn to love everyone unconditionally. When helping others, they barely anticipate to be rewarded, especially in the tangible means.

From question 7, we see that when receiving a gift, more Germans $(60 \%)$ than Chinese $(50 \%)$ care about the suitability of the gift, while more Chinese $(16.37 \%)$ than Germans $(0 \%)$ care about the practicality. This might be another sign to show the Chinese people are more pragmatic than the Germans.

The results of question 8 are a little shocking but understandable. When invited to their boss's birthday party, $26.67 \%$ Chinese would give expensive presents while only $3.33 \%$ Germans would do so. Both are countries with high power distance (Samovar, Porter, \& Stefani, 2000), but the way they deal with the relationship with their leaders is quite different. We think this may attribute to the fact that China used to be a very traditional society based on hierarchies ruled over by feudal powers, and currying favor with higher-ups was often the only way to protect oneself, to get wrongs readdressed, or to obtain basic rights. It is indeed the "Guanxi" (relationship/connection) orientation that dominates people's behavior. Under this "Guanxi" influence, it seems to be a very good opportunity to give expensive gifts to one's boss to further the relationship (Boye Lafayette De Mente, 1989; Hu \& Grove, 1991; Seligman, 1999). But the Germans are influenced by individualism and equality, therefore they have clear-cut lines between public and private interests. Though there is high power distance between the leaders and their employees in Germany, the employees would rarely think of getting any concrete benefits in work by establishing a close relationship with their leaders. However, it should be noted here that now in China, the young generation might have been very much affected by the Western cultures and values, so this practice is likely to become less and less. That may be why only $26.67 \%$ of the Chinese would do so.

Findings from question 10 show that when giving gifts to others, $63.63 \%$ of the Chinese would not tell the price while $36.67 \%$ of them would do so if the gift is expensive or valuable. Contrarily, there are $90 \%$ of Germans choosing never to tell the price and only $10 \%$ of them would tell. Comparatively speaking, more Chinese regard the amount of money as tokens of showing the depth of a relationship. Again, it seems to reveal that in current China, money is meaning and in Germany, the intent is meaning.

\section{Interviews}

The researcher firstly had an in-depth interview with her friend Stefan and he explained that in Germany, people normally do not send an expensive present to a friend, even if he might be a very good one. Instead, many people would use self-made gifts to show the particular feeling attached to the gift. If the gift fits the recipient, they do not mind whether the price is high or low. They are happy to help others and regard it as a pleasure without expecting any material reward. If someone suddenly sends him an expensive present, it is actually very dangerous and harmful to their relationship, because the recipient would think he does not deserve such a "big" present and feel his face is endangered. He would inevitably ask, "Why?" In Li's case, he felt really bad because (1) he knew Li was a poor student, who needed money to survive, and he did not want to worsen his life and (2) he went shopping with $\mathrm{Li}$, so he knew the price and it was like choosing a present for himself! If he had known the present was for him, he might have thought differently and would have chosen something else which he really fancied and was inexpensive. In Germany, people give presents but will never

\footnotetext{
1 The Bible (new international version) Luke 6: 35 .
} 
tell the recipient the price. The recipient cares more about the suitability of the present than the price or other things. So there is no problem if your present is inexpensive or not a famous brand. At that time, he felt extremely uncomfortable and embarrassed accepting the present, but on the other hand he knew he had to accept it, otherwise he might hurt his Chinese friend so deeply as to lose him, which he did not hope to happen. He just felt he could not accept the gift without a serious talk with Li. By interviewing three other Germans, the researcher found they practically all agree with Stefan.

Interviews with the four Chinese participants basically verify the researcher's assumptions and speculations about their choices in the questionnaire, which have already been discussed in the analysis of the questionnaire section.

\section{Conclusions and Implications}

From the above-mentioned analysis and discussions, we seem to be able to draw the following conclusions:

(1) Gift-giving still remains an important aspect in creating and nurturing relationships with people in China, though people are becoming less tradition-bounded and more individualistic under the western cultures;

(2) The Chinese people are more pragmatic than the Germans in interpersonal communication, and they like to express abstract feelings, thoughts, or appreciations in tangible ways, such as gifts;

(3) In current China, money is meaning, while in Germany, intent is meaning.

Based on the research findings and the conclusions, the author believes the following implication would be fairly useful and helpful in intercultural foreign language teaching:

It is widely acknowledged that the traditional agricultural culture has molded China into a society with a hierarchical structure sustained mainly by blood relations, which necessarily made interpersonal relationship in the Chinese culture characterized by group orientation and hierarchical structure (HU \& Grove, 1991). Therefore, "Guanxi" (connection or relationship) has become the most important communicative principle during the process of interpersonal communication. So important is the relationship that it goes so far for the Chinese as to do almost everything by it. This "relationship" principle has played a significant role on the communicative behavior and style. According to the Confucianism, the ultimate goal of human behavior is to achieve "harmony" which leads Chinese people to pursue a conflict-free and group-oriented system of human relationship. One's social relationships can directly influence his social status. The broader one's relationship web is, the more useful relationships one might have, and the more authoritative and influential one could be in others' eyes, therefore one would gain more face (HU \& Grove, 1991). In practice, this is displayed by the emphasis on human sentiment and face. The principle "Li shang wang lai" (Courtesy demands reciprocity) is actually advocating mutual indebtedness and the concept "you do things for me and me for you" (HU \& Grove, 1991). These rooted traditional values are still affecting the young generations in China though much more slightly than before. It also proves that the deep value systems in a culture cannot be easily changed.

On the other hand, the Western culture in which German culture is nurtured has developed from the ocean culture, a culture that is based on contractive relationship and is individualism-oriented. It highlights greatly on the equal or parallel relationships. Therefore, the interpersonal relationships in Western countries are instrument-based or function-based (Samovar, Porter, \& Stefani, 2000). They are not driven by human sentiments and seldom give consideration to what we Chinese call "ren qing" (human sentiment) and face. They do things in accordance with the "equality principle", rules and laws. Even with relatives, they are clear in 
distinguishing "people" from "things", namely public and private interests. Westerners are unlike the Chinese who normally utilize human sentiment as a means of doing things. For the Westerners, the establishment of human sentiment and friendship is generally unconditional. Reason and logic often surpass sentiment (JIA, 1997).

Armed with a better understanding of the different practices of gift-giving across different cultures, foreign language teachers may become more actively and consciously involved in raising learners' IC awareness and IC competence, which the author firmly believes, will not only assist learners in coping with the similar social occasions more smoothly, pleasantly, and successfully, but also will undoubtedly and invariably lead to a more desirable and efficient teaching and learning effect.

Finally, the author would like to remind the readers that this study is a tentative one. The results of the available research are suggestive rather than definitive. The researcher has strong reasons to believe that this area needs to be further studied.

\section{References}

Boye Lafayette De Mente. (1989). Chinese Etiquette \& Ethics in Business. Chicago: NTC Business Books.

Gudykunst, W., \& Kim, Y. Y. (2007). Communicating with strangers: An approach to intercultural communication (4th ed.). Shanghai: Shanghai Foreign Language Education Press.

Hall, E. T. (1959). The silent language. New York: Doubleday.

HU, W. Z., \& Cornelius, G. (1991). Encountering the Chinese: A guide for Americans. Yarmouth, Maine: Intercultural Press, Inc. (USA).

JIA, G. D. (2015). Carrying forward the reform achievement and building up the innovative development: On appreciating the guidelines for college English teaching. Foreign Languages in China, 4, 4-9.

JIA, Y. X. (1997). Intercultural communication. Shanghai: Shanghai Foreign Languages Education Press.

Samovar, L. A., Porter, R. E., \& Stefani, L. A. S. (2000). Communication between cultures. Beijing: Foreign Language Teaching and Research Press.

Seligman, S. D. (1999). Chinese business etiquette. New York: Warner Books, Inc..

ZHANG, H. L. (2007). Intercultural approach to foreign language teaching. Shanghai: Shanghai Foreign Language Education Press. 
Appendix: A Questionnaire About the Perceptions of Present-Giving

Nationality: sex:

Age: 15-20 ( ) 20-25 ( ) 25-30 ( ) 30-35 ( ) above 35 ( )

In the questionnaire below you will read 6 statements. Please answer them and put your choice in the brackets. Use the abbreviations as shown below:

(5) means you strongly agree with the statement (4) means you agree, but not strongly

(3) means you are uncertain about the question (2) means you disagree with the statement

(1) means you strongly disagree

( ) 1. Presents are important measures for proving if I am taken seriously in another's heart.

( ) 2. When sending presents to my friends, I usually choose presents of different prices according to the degree of relationship between us. The closer a friend is, the more expensive the present will be.

( ) 3. If a friend sends me a birthday present which I like very much but is quite expensive, I would think he/she has already regarded me as a close or special friend. Though I would feel extremely flattered, I would accept it and feel I've gained lots of face.

( ) 4. When sending a present to a friend, a colleague or someone else, I won't consider the price of the present too much. Instead, I care more about if this present is suitable or meaningful to him or her.

( ) 5. If possible, I'd rather make a present by myself because self-made gift is more personal and precious.

( ) 6. If a friend has been helping me a lot for nothing, I usually would send him/her an expensive present on a proper occasion to show my deep appreciation.

(Please choose the only answer that suits your situation)

( ) 7. Whenever my boyfriend/girlfriend or spouse sends me a present, I care more about

A: The practicality of the gift B: Whether it is suitable C: The price of the gift D: I don't care.

( ) 8 . When invited to my boss's birthday party, I would

A: Choose a present which I think he/she just needs but is not expensive.

B: Send something fashionable and trendy. So long as my boss is pleased, I wouldn't mind the price.

C: Send an expensive present to show my respect and support for him/her

D: Send something casually without much consideration

( ) 9. When sending presents to my parents or siblings, I would

A: Choose a present which I think he/she just needs but is not expensive.

B: Send something fashionable and trendy, wouldn't mind the price.

C: Send an expensive present to show my love for them.

D: Send something casually without much consideration

( ) 10. when giving a present to others, I would deal with the price of the gift in this way:

A: never tell the price B: indicate the price if it's high in order to show my friendship

C: won't tell the price if it's cheap D: tell it anyway

( ) 11. Your viewpoint of sending presents to others is:

A: Very important. It's an effective way to improve relationships.

B: Important. But it depends on whom to send to, what to send and how to send it.

C: Not very important. It's just a matter of formality.

D: Not important at all. It's no more than a waste of time and money. 